\title{
Characterization of Global Near-Nadir Backscatter for Remote Sensing Radar Design
}

\author{
Michael W. Spencer \\ California Institute of Technology, Jet Propulsion Laboratory \\ MS 300-319, 4800 Oak Grove Dr., Pasadena CA 91109-8099 \\ 818-354-1175, mwsQshiokaze.jpl.nasa.gov
}

David G. Long

Brigham Young University, MERS Laboratory

459 CB, Provo, UT 84602

Abstract - In order to evaluate side-lobe contamination from the near-nadir region for Ku-Band radars, a statistical characterization of global near-nadir backscatter is constructed. This characterization is performed for a variety' of surface types using data from TRMM, Seasat, and Topex. An assessment of the relative calibration accuracy of these sensors is also presented.

\section{INTRODUCTION}

Off-nadir looking radar instruments are often vulnerable to side-lobe "clutter" contamination from the near-nadir region (see Fig.1). For pencil-beam scatterometers, such as the SeaWinds instrument to be flown on QuikSCAT in 1999 , suppression of the strong return from the nearnadir region is important to insure that the wind measurements do not suffer from excessive contamination. Because pencil-beam scatterometers typically have multiple transmit pulses and return echoes in flight, care must be taken in the scatterometer design to insure that the nearnadir return is sufficiently attenuated if it arrives at the same time as an off-nadir pulse. The most sure way to alleviate the specular region contamination problem, without placing undue constraints on the pulse timing scheme, is to insure that the antenna side-lobe levels in the direction of nadir sufficiently suppress this signal.

In this paper, the strength of the near-nadir region backscatter for a variety of globally encountered surface conditions is examined. This characterization is performed empirically using data from spaceborne radar missions that obtained near-nadir measurements. Given the "worstcase" nadir return strength, conservative antenna sidelobe requirements can be derived.

\section{KU-BAND NADIR-LOOKING RADAR DATA SETS}

To assess potential Ku-Band contamination from nadir, we first construct a statistical characterization of global normalized backscatter cross-section $\left(\sigma^{\circ}\right)$ at low incidence angles (0-18 degrees). Data collected from three different sensors are examined: the Tropical Rainfall Measurement Mission (TRMM) Precipitation Radar (PR), the Seasat-A Scatterometer System (SASS), and the Topex Altimeter. Taken together, these data sets allow a thorough charac-

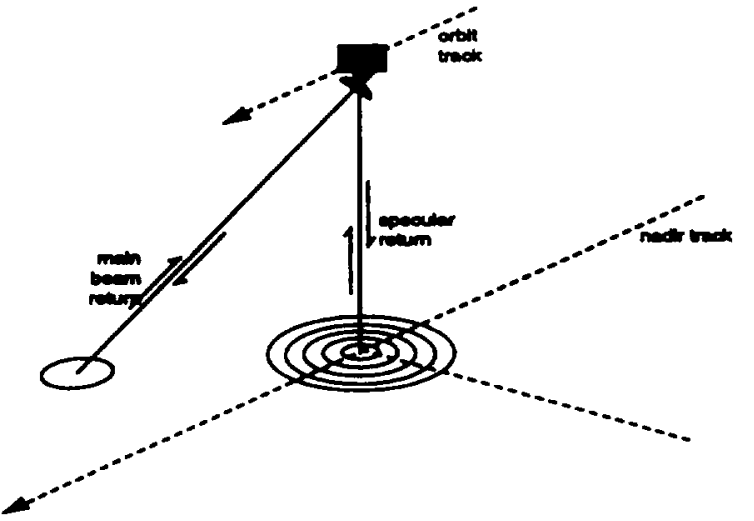

Figure 1: Near-nadir return contamination geometry.

terization of near-nadir backscatter over a wide range of surface conditions and seasonal variations.

\section{A. TRMM Rain Radar}

In addition to profiling rain, the TRMM PR measures surface $\sigma^{\circ}$ at $\mathrm{H}$-polarization in the incidence angle range of 0-18 degrees [4]. The measurement resolution, cross-track spacing, and along-track spacing are all approximately 4 $\mathrm{km}$. The TRMM PR covers the latitude band between $\pm 35^{\circ}$. For convenience throughout this paper, we will refer to this region as "tropical," even though it technically extends well into the mid-latitudes. The region above $\pm 35^{\circ}$, which includes the polar regions, we refer to as "extra-tropical."

In Fig. 2, a one day scatter plot of typical TRMM PR $\sigma^{\circ}$ data is shown for both water and land scenes. The mean backscatter behavior over the ocean can be modeled as an undulating collection of surface facets of varying slopes [3]. On occasion, particularly in sheltered areas where wind and swell are damped, near-specular scattering occurs, causing $\sigma^{\circ}$ values to spike up near nadir $\left(<5^{\circ}\right.$ incidence) and decrease sharply further off-nadir $\left(>5^{\circ}\right)$. The behavior over land is consistent with a widely varying target, corresponding to the different terrains encountered - forests, desserts, cities, mountain slopes, lakes, etc. The land backscatter exactly at nadir is often dominated by a strong surface specular return. Although the mean $\sigma^{\circ}$ over ocean is larger than land, the much higher variance of the land values have the effect of making the peak values 
at each incidence angle approximately the same for both water and land.
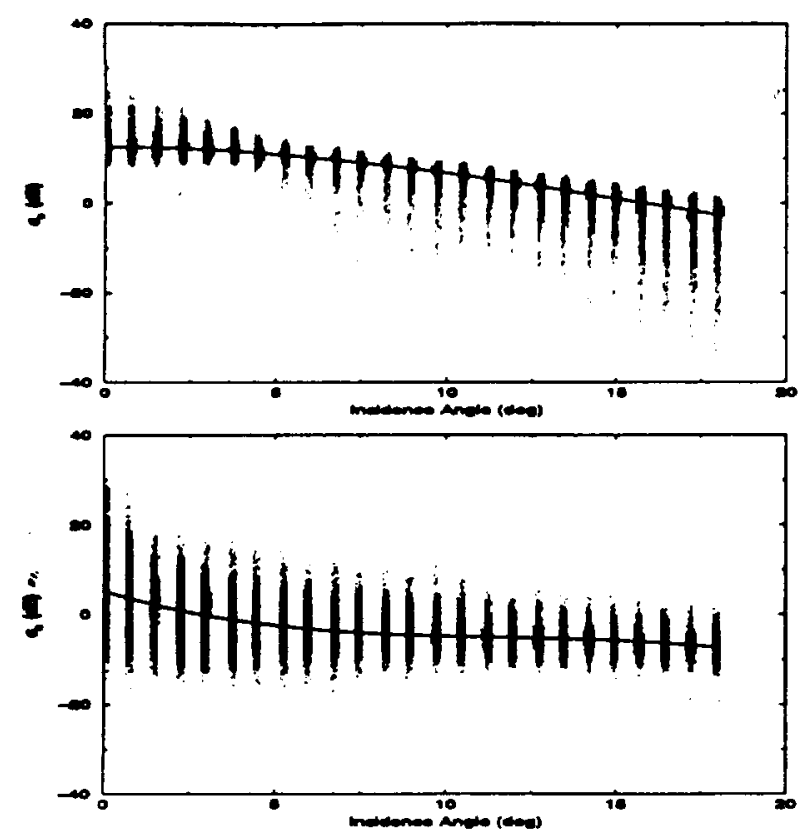

Figure 2: Sample scatter plots of TRMM $\sigma^{\circ}$ vs. incidence angle from July, 1998 for (a) ocean and (b) land. Also shown is a third order curve fit to the data.

There are limitations with using the TRMM data set to characterize global backscatter. As of the September 1998 TRMM reprocessing, the dynamic range is limited so that no backscatter values above $28 \mathrm{~dB}$ are reported. Although rare, such backscatter values are known to occur at nadir. The PR coverage is also limited to a "tropical" latitude range. This is problematic because new sea ice is known to be a very bright target at nadir. For these reasons, the complementary data set provide by Seasat is examined as well.

\section{B. SASS Near-Nadir Measurements}

The Seasat-A Scatterometer System (SASS) flew from June 28, 1978 until a satellite failure ended the measurements on October 10,1978. In addition to the standard Bragg-regime measurements made to determine wind, SASS also collected measurements of nadir region backscatter near $0^{\circ}, 4^{\circ}$, and $8^{\circ}$ incidence [1]. These measurements were collected at both $V$ - and H-Polarization, with each measurement cell having spatial dimensions of approximately $10 \mathrm{~km} \times 50 \mathrm{~km}$. The Seasat spacecraft flew in a more inclined orbit than TRMM and thus collected measurements up to $\pm 72^{\circ}$ in latitude.

To illustrate how the SASS data from the extra-tropical region complements the tropical data, normalized histograms of $\sigma^{\circ}$ from July 1978 for incidence angle ranges of $0-1$ degrees and 3-4 degrees are displayed in Fig.s 3(a) and 3 (b) respectively. Distributions for ocean tropical, ocean

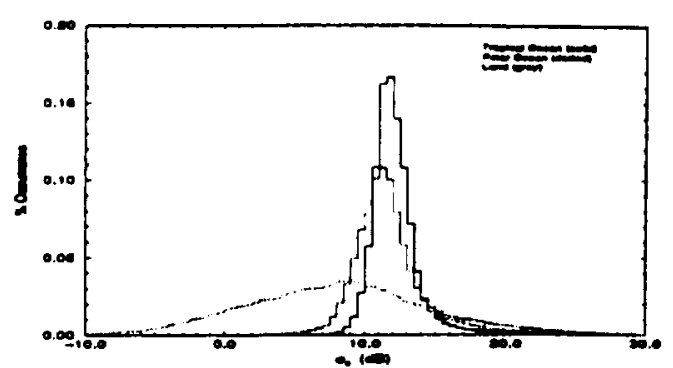

Figure 3: (a) SASS 0-1 deg incidence.

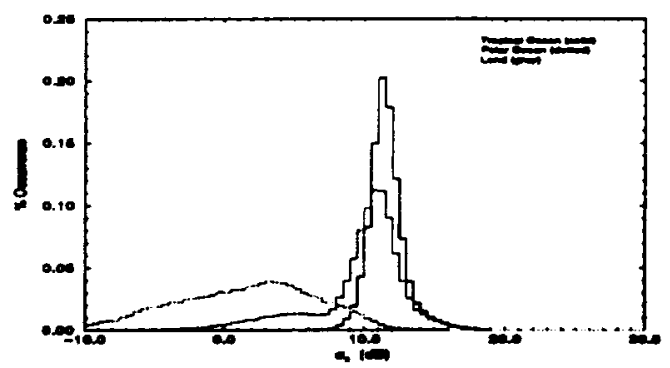

Figure 3: (b) SASS 9-1 deg incidence.

extra-tropical, and combined land $\sigma^{\circ}$ are shown. Importantly, we note that the SASS data collected here has not been flagged for sea ice, so the extra-tropical data contains both open ocean and sea ice areas. In July, it is expected that the antarctic ice sheet is reaching its greatest extent and the arctic ice sheet is in a melting stage. In Fig. 3(a), we observe that the peak of the extra-tropical ocean distribution is about $1 \mathrm{~dB}$ lower than the tropical ocean distribution - likely caused by the higher winds and consequently lower nadir backscatter at high latitudes. The extra-tropical ocean distribution, however, has a pronounced high $\sigma^{\circ}$ "tail" which indicates a much greater probability to produce strong specular returns. This tail is most likely due to the presence of new sea ice in the antarctic, which forms a very flat specular surface, and melting ice in the arctic, where enclosed areas of calm water form. At the off-nadir angles in Fig. 3(b), however, the extended distribution tail reverses positions and exhibits a higher probability for lower backscatter values. These observations are consistent with very smooth surfaces where specular scattering dominates [2].

\section{Topex Altimeter $\sigma^{\circ}$ Data}

Although designed for the measurement of sea surface height, spaceborne altimeters also measure surface backscatter cross section. Altimeter measurements, however, are generally insufficient for a complete characterization of near-nadir backscatter, due to the fact that the $\sigma^{\circ}$ measurements are only collected at $0^{\circ}$ incidence. In this analysis, data from the Topex altimeter, a successful mission which has been operated continuously for a number of years, is included primarily for a calibration validation of the other instruments. 


\section{COMPARISON AND FUSION OF DATA SETS}

To gain confidence that we can "fuse" the data from the various data sets discussed above to form a complete description of near-nadir backscatter over a range of incidence angles, polarizations, and Earth locations, we first wish to validate that the instruments are calibrated sufficiently accurately relative to one another. Figure $4 \mathrm{com}$ pares the mean ocean backscatter of the three sensors. The SASS and TRMM data are third order fits to the data as a function of incidence angle, and the one Topex point is the mean value at nadir. Note that the sensors agree to within $1 \mathrm{~dB}$ or better. Also note that the V-pol and H-pol curves from the SASS are within $0.3 \mathrm{~dB}$ of each other.

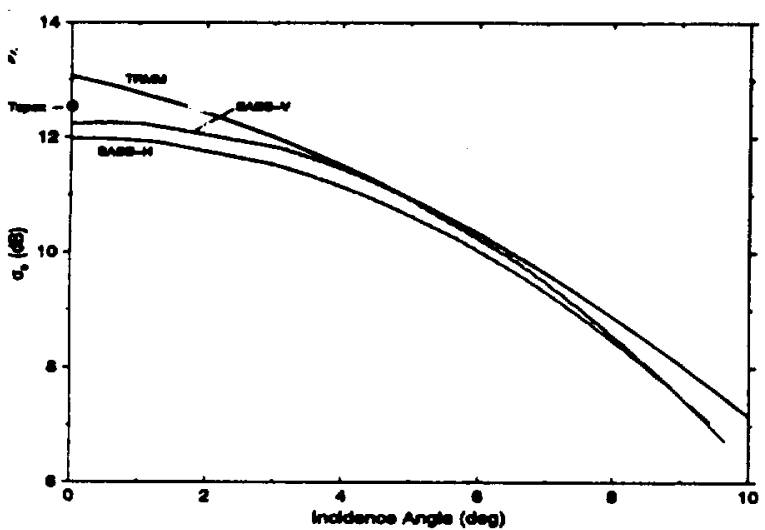

Figure 4: Comparison of July mean tropical ocean backscatter of TRMM, Topex, and SASS ( $B$ - and V-pol).

Taking the TRMM and SASS data sets collectively, we construct a global model of near-nadir backscatter. Such a model, expressed in terms of mean and "peak" backscatter values encountered at each incidence angle is shown in Fig. 5. Here the mean curve has been constructed as a fit to both the SASS global and TRMM tropical data, where weighting has been applied to account for both the relar tive frequency of measurements in each data set and for the percentage of the Earth's surface that each data set covers. The "peak" backscatter is represented by the 99th percentile high backscatter observed at each incidence angle. The peak curve will be used to assess the "worst-case" near-nadir contamination.

It is important to briefly elaborate on the meaning of "peak" backscatter at incidence angles very close to $0^{\circ}$ incidence. For a highly specular surface, the effective $\sigma^{\circ}$ varies rapidly with incidence angle and thus becomes a strong function of both the footprint area and range of incidence angles illuminated [2]. The nadir peak values shown in Fig. 5 are consistent with an integrated $\sigma^{\circ}$ value in a region $1^{\circ}$ from nadir.

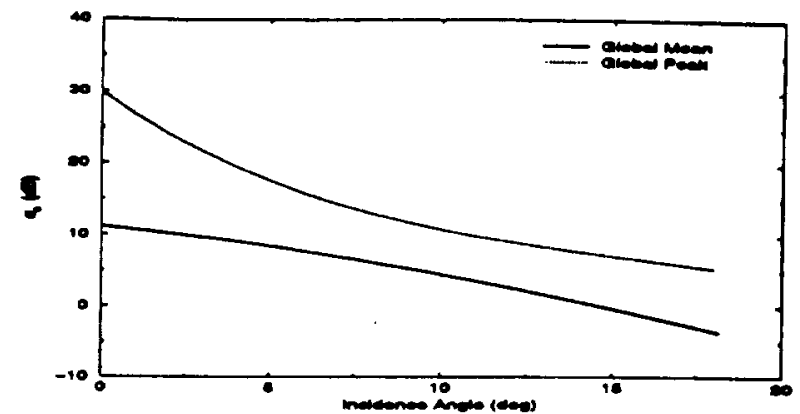

Figure 5: Global mean and peak (99th percentile) nearnadir backscatter profiles.

\section{CONCLUSIONS}

Using the peak values from Fig. 5, we integrate over the entire near-nadir region to calculate the "worst-case" contamination which leaks into the antenna sidelobes. It is found that, for a pencil-beam scatterometer, the nadir return may be adequately suppressed if the side-lobes in the direction of nadir are $44 \mathrm{~dB}$ below the peak gain. For a SeaWinds class instrument, this is achievable because the direction of nadir is many beamwidths away from the boresight direction. Recall that Fig. 5 represents the peak $\sigma^{\circ}$ at each incidence angle independent of the values at other incidence angles. Thus, for a truly realistic analysis, a joint distribution for $\sigma^{\circ} s$ is desired. This issue is currently being addressed.

\section{REFERENCES}

[1] E.M. Bracalante, D.H. Boggs, W.L. Grantham, J.L. Sweet, "The SASS Scattering Coefficient $\sigma^{\circ}$ Algorithm," IEEE J. of Oceanic Eng., Vol. OE-5, No. 2, April 1980.

[2] F.M. Fetterer, M.R. Drinkwater, K.C. Jezek, S.W. Laxon, R.G. Onstott, L.M. Ulander, "Sea Ice Altimetry," in Microwave Remote Sensing of Sea Ice, F.D. Carsey Ed., AGU Geophysical Monograph 68, 1992.

[3] R.E. Glazman and S.H. Pilorz, "Effects of Sea Maturity on Satellite Altimeter Measurements," JGR, Vol. 95, No. C3, pp. 2857-2870, March 1990.

[4] C. Kummerow, W. Barnes, T. Kozu, J. Shiue, and J. Simpson, "The Tropical Rainfall Measuring Mission (TRMM) Sensor Package," J. of Atmos. and Oceanic Tech., Vol. 15, No. 3, pp. 809-817, June 1998.

\section{ACKNOWLEDGMENTS}

The work reported here was performed at the Jet Propulsion Laboratory, California Institute of Technology under contract with the National Air and Space Administration. 